\title{
Evaluation of the Effect of an Independent Support Type Pelvic Fixation System Dining Chair Corresponding to Eating and Drinking Troubles of Elderly People who Continue to Decline in Swallowing Function
}

\author{
Junichi Fukaura $^{1}$, Tetsushi Tamekazu ${ }^{2 *}$, Hideo Kaneko ${ }^{2}$, Takeshi Nanba ${ }^{2}$, Yasuhiko Takeda ${ }^{3^{*}}$ \\ ${ }^{1}$ Department of the Japan Speech and Hearing sciences Association, The Dysphagia Rehabilitation Society Councilor, Japan; \\ ${ }^{2}$ Department of Rehabilitation (Speech and Hearing Sciences and Physical Therapy), International University of Health and Welfare \\ Graduate School Fukuoka, 137-1 Enokitsu Okawa City Fukuoka pre. 831-8501, Japan; ${ }^{3}$ Department of Rehabilitation (Speech and \\ Hearing Sciences and Physical Therapy), International University of Health and Welfare Graduate School Fukuoka, Association of \\ Development of welfare equipment, 2-109 Honmachi Tottori City, Tottori pref. 680-0031, Japan
}

\begin{abstract}
The smooth swallowing posture (neck forward flexion posture) and swallowing function training to correspond to the aspiration are described in the medical literature. How to make neck forward flexion(NFF) posture and how to keep NFF posture is the biggest unresolved problem of dining chair development for researchers and developers in medicine and engineering. A dining chair designed to protect the elderly from aspiration and aspiration pneumonia was developed in Japan. We thought that if the function effect of the dining chair was truly demonstrated, it would be valuable information to all the elderly who have troubles in daily meal. We tried to verify the actual effect of the functional structure of the dining chair with electromyograph. As a result of the verification, it was confirmed that the meal with a new posture fixation system exhibited a smooth swallowing effect. The verification result of the dining chair of the new method is nice information for all the elderly in the world who continue to decline swallowing function.
\end{abstract}

Keywords: Dining chair; Smooth swallowing; Neck forward flexion; Aspiration; Elderly

\section{INTRODUCTION}

In Japan, the aspiration and the aspiration pneumonia of the elderly continue to increase every year, and it becomes a big social problem. The elderly person over 70 years old who is hospitalized with the aspiration pneumonia which is one of the three major causes of death is 20,000 people per day [1]. There are many medical documents on eating posture and swallowing training to prevent aspiration. The correct dietary posture is defined in six items by [2]. But how to make an NFF posture, and how to maintain an NFF posture is the biggest unresolved problem in the development of dining chairs for ergonomics researchers, rehabilitation researchers and manufacturers. A dining chair has been developed in Japan that has cleared all six items defined by Dr. Siebens.
The developed chair was a new system dining chair that keeps the upright pelvic ischial tuberosity and posterior superior iliac spine (PSIS) fixed on the seat and seat back to keep the NFF posture. Also, this was dining chair with a function to support the independence of the elderly which substitute of the eyes and hands of caregiver to watch over the eating posture of the elderly [3]. In order to start comparison and verification, we obtained a new finding that the most efficient desk work posture(NFF sitting posture) is a state where the angle 100 degrees chair back seat and the two PSIS contact exquisitely [4]. We tried to verify the functional structure of the world's first NFF posture maintaining dining chair and its effects, which influence over to the smooth swallowing of elderly people whose swallowing function continues to decline. For the verification tests, we tried a comparative verification test between a general dining chair and a developed dining chair for smooth swallowing with an

"Correspondence to: Tamekazu T, Department of Rehabilitation: (Speech and Hearing Sciences and Physical Therapy) International University of Health and Welfare Graduate School Fukuoka,137-1 Enokitsu Okawa City Fukuoka pre. 831-8501, Japan, Fax: 0944-89-2001,Tel: 0944-89-2000; Email: tame@iuhw.ac.jp

Takeda Y, Department of Rehabilitation: (Speech and Hearing Sciences and Physical Therapy) International University of Health and Welfare Graduate School Fukuoka, Association of Development of welfare equipment, 2-109 Honmachi Tottori City, Tottori pref. 680-0031 Japan, Tel: 0857-29-6281; Email:takeda-y@enjoy.ne.jp

Received: May 28, 2019, Accepted: June 7, 2019, Published: June 14, 2019

Citation: Fukaura J, Tamekazu T, Kaneko H, Nanba T, Takeda Y (2019) Evaluation of the Effect of an Independent Support Type Pelvic Fixation System Dining Chair Corresponding to Eating and Drinking Troubles of Elderly People who Continue to Decline in Swallowing Function. J Aging Sci 7:205. doi: 10.35248/2329-8847.19.07.205

Copyright: (c) 2019 Fukaura Y, et al. This is an open-access article distributed under the terms of the Creative Commons Attribution License, which permits unrestricted use, distribution, and reproduction in any medium, provided the original author and source are credited. 
electromyograph as a method considered to be able to obtain the most objective evaluation [5].

\section{CASE REPORT}

The verification test was aimed at the healthy elderly of 11 men and 10 women over the age of 65 who are living independent daily life without cerebrovascular disorder and dysphagia. The verification test was conducted with a document and a verbal explanation to all subjects, and a verification test after obtaining a written signature.

\section{neck forward flexion posture} holding function dining chair

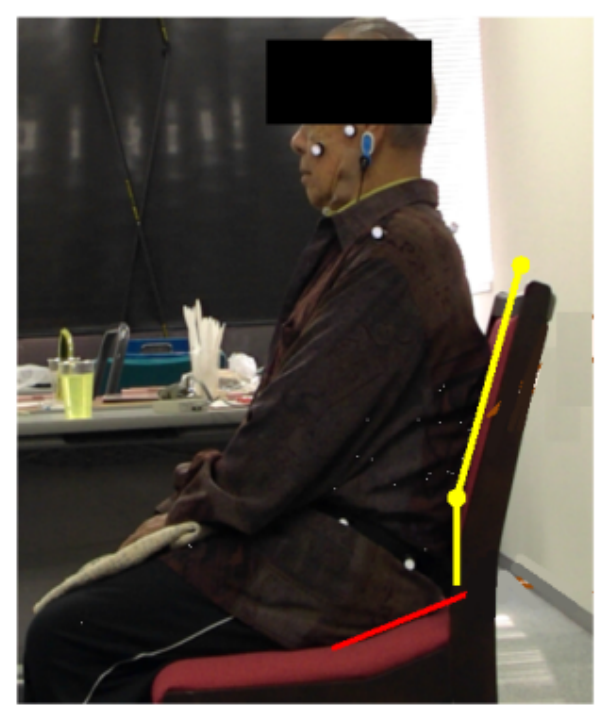

NFF posture holding function dining chair,

The backrest (height $45 \mathrm{~cm}$ ) is inclined backward 10 degrees until the bottom $20 \mathrm{~cm}$ and backward inclined 20 degrees in the upper part.

The seat surface (depth $40 \mathrm{~cm}$ ) ischial tuberosity peripheral portion is in a concave shape.

This study has obtained the approval of the international medical and Welfare University Ethics Review Committee (approval number: 15-IFH-3).

Using the NFF posture holding function dining chair, and the general dining chair, measured EMG of the swallowing muscle during jelly swallowing (Figure 1).

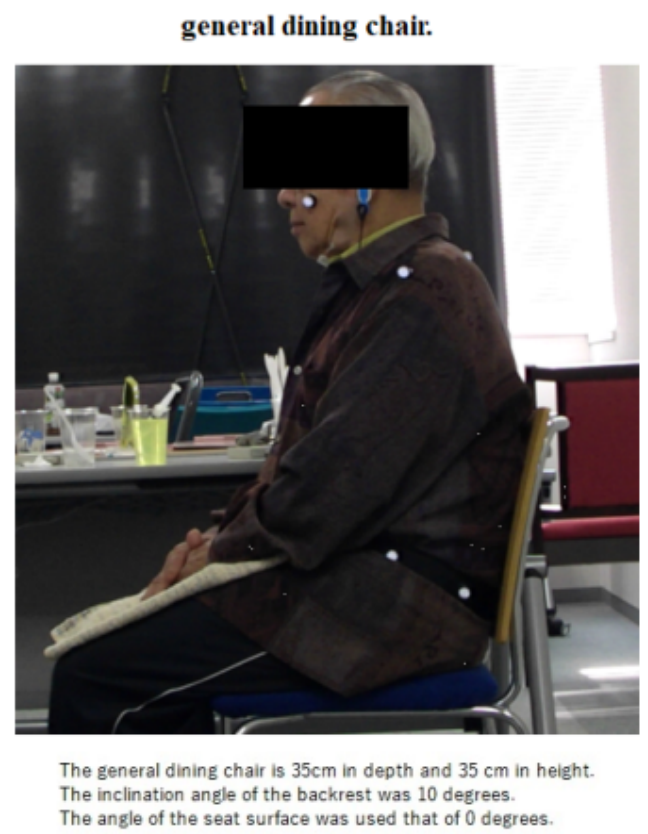

Figure 1: The NFF posture holding function dining chair and general dining chair.

The examinations were conducted by two groups, one who manipulates the electromyograph and the other who puts the jelly in the oral cavity of the subject. The swallowing measurement was performed after explaining that $5 \mathrm{cc}$ jelly was swallowed without chewing. Measurement for verification was swallowed three times each with two kinds of chairs and the order of the measurements was random.

The anterior belly of digastric muscle of the suprahyoid muscles surrounded by mental protuberance and mandible were recorded EMG as a swallowing muscle [6]. Recording electrodes, the Mets Inc. Blue Sensor as the electrode width $20 \mathrm{~mm}$, was affixed to the surface skin along the muscle fibers after pretreatment with alcoholic cotton. The non-function electrodes were affixed to the earlobe. The electromyograph was using the EMG Master Km-mercury (manufactured by Mediarea Support Company Union Co., Ltd.). The sampling frequency after fullwave rectification at $1 \mathrm{kHz}$, was subjected to low-pass filter processing (cutoff frequency $5 \mathrm{~Hz}$ ). For the calculation of the suprahyoid muscles activity duration during swallowing, the point where the waveform became the average amplitude $+2 \mathrm{SD}$ or more of the baseline was sustained between $50 \mathrm{~ms}$ muscle activity starting point, the following point was calculated as muscle activity end point (Figure 2).

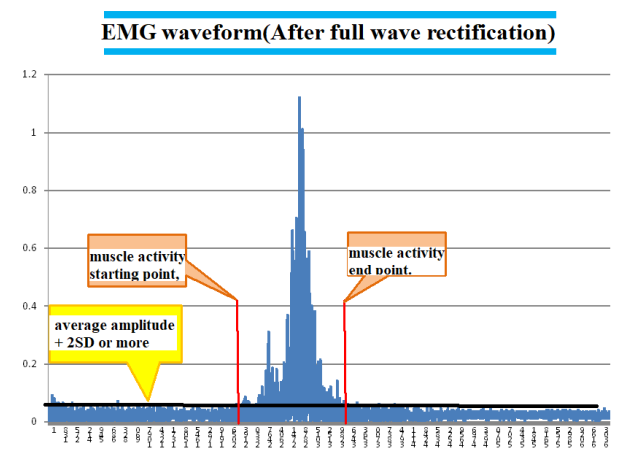

Figure 2: Electromyogram waveform.

The statistical test was performed with a correspondence TTest.The statistical software used SPSS (Ver.19), and the risk rate was significant with less than $5 \%$. 
8 people were not able to analyze the waveform of the EMG, and finally analyzed the results of 13 subjects (average age 72.23

\pm 6.01 years) of 10 male 3 women (Table 1 ).

Table 1: Measurement results of the subject.

\begin{tabular}{|c|c|c|c|c|c|c|}
\hline \multirow{2}{*}{ Sl. no. } & \multirow{2}{*}{ Sex } & \multirow{2}{*}{ Age } & \multirow{2}{*}{ Height (cm) } & \multirow{2}{*}{ Body weight $(\mathrm{kg})$} & \multirow{2}{*}{$\begin{array}{l}\text { Suprahyoid muscle group } \\
\text { activity time (sec) (average of } \\
3 \text { measurements) }\end{array}$} & \multirow{2}{*}{$\begin{array}{l}\text { Suprahyoid muscle group } \\
\text { activity time (sec) (average of } 3 \\
\text { measurements) }\end{array}$} \\
\hline & & & & & & \\
\hline 1 & Female & 73 & 148 & 45 & 1.13 & 2.1 \\
\hline 2 & Female & 71 & 153 & 52 & 0.33 & 0.56 \\
\hline 3 & Female & 65 & 160 & 63 & 0.5 & 0.7 \\
\hline 4 & Male & 73 & 168 & 53 & 0.38 & 1.31 \\
\hline 5 & Male & 81 & 164 & 68 & 0.9 & 0.75 \\
\hline 6 & Male & 77 & 167 & 60 & 1.125 & 0.5 \\
\hline 7 & Male & 72 & 165 & 52 & 0.71 & 0.78 \\
\hline 8 & Male & 81 & 156 & 65 & 1.45 & 1.6 \\
\hline 9 & Male & 80 & 160 & 45 & 1.83 & 2.03 \\
\hline 10 & Male & 67 & 168 & 63 & 1.45 & 1.81 \\
\hline 11 & Male & 69 & 169 & 71 & 2.13 & 2.38 \\
\hline 12 & Male & 65 & 181 & 59 & 1.98 & 2.71 \\
\hline 13 & Male & 65 & 165 & 65 & 0.91 & 1.05 \\
\hline Average & & 72.23 & 163.38 & 58.53 & 1.14 & 1.43 \\
\hline
\end{tabular}

Suprahyoid muscles activity duration showed a significant difference in NFF posture holding function dining chair $1.13 \pm$ 0.59 seconds, general dining chair $1.43 \pm 0.77$ seconds (Pvalue $=0.045<0.05)$ (Figure 3).

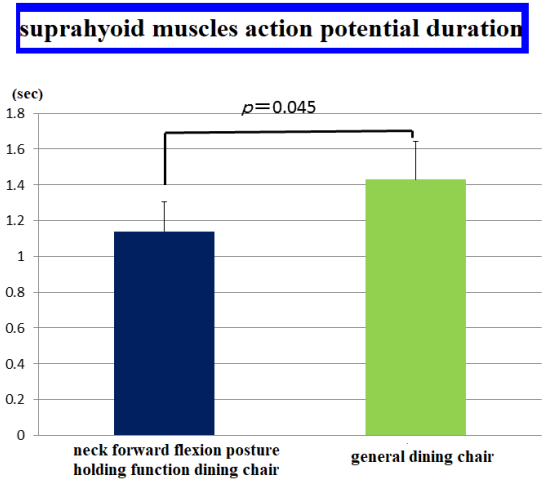

Figure 3: Suprahyoid muscles activity duration.

\section{DISCUSSION}

In order to keep the pelvis upright, the activity of the iliopsoas muscle is essential, and the iliopsoas muscle has an action to bend the hip joint. If to try to hold the NFF's sitting posture in a general chair sitting position, the hip joint will bend further and the sole will try to move away from the floor surface. In the case of middle-aged and elderly people with declining trunk and lower extremity muscles, sitting posture for eating falls into an unstable situation. It is considered that the activity duration of the suprahyoid muscles is extended because it was difficult to maintain a desirable NFF eating posture in a general dining chair. For the case of a new system dining chair that allows stable holding of the desired NFF feeding posture by supporting the upright pelvis at both the ischial tuberosity and both PSIS sections. It is thought that the chair that stably holds the NFF eating posture can realize shortening of the activity duration of the suprahyoid muscles by not requiring excessive iliopsoas muscles activity. 
NFF posture holding function dining chair was significantly shorter than the general dining chair in the suprahyoid muscles activity time [7]. Though eight subjects were unable to measure and analyze due to the thick subcutaneous fat at the measurement point, the swallowing test by the muscle measurement may the most objective verification method that was not influenced by the individual subjectivity of the tester and the subject. From the measurement results by electromyography, the NFF posture was a posture that enables ideal smooth swallowing that satisfies the 6 items defined by Dr. Siebens [8]. Also, from ergonomic viewpoint, NFF posture fixation in the pelvic area of the new system reduces postural collapse(forward slide suppression of ischial tuberosity) in the eating movement, and facilitates phlegm expulsion for crisis avoidance with the freely back-and-forth movement of upper body(high postural holding ability and high crisis avoidance ability) [9]. The NFF posture-holding chair with independence support function is expected to provide safe and smooth swallowing meals to elderly people, especially the solitary elderly, and older couples who do not have families or caregivers to monitor their eating posture. We will expect future verification about the remarkable difference between the suprahyoid muscles action potential duration and the posture holding ability depending on the time history of the posture holding function dining chair and the general dining chair. Since this experiment was subjected of healthy subjects, it is necessary to further verify whether those with cerebrovascular disorder, dysphagia and dementia will lead to similar results.

\section{CONCLUSION}

NFF posture holding function dining chair was significantly shorter than the general dining chair in the suprahyoid muscle Grouper's activity time. From the results of the verification test, stable NFF posture is kept in the state where ischial tuberosity and PSIS of the upright pelvis are held in the chair seat face and backrest. As a result of the measurement by electromyograph, the diet at the NFF posture was re-demonstrated to be an eating posture for difficult aspiration and smooth swallowing. The measurement of the posture did not appear noticeable difference in that it was performed immediately after the start of the verification test.

Since this experiment was subjected to subjects of healthy subjects, whether dysphagia patients such as cerebrovascular disease becomes similar results, it is necessary to further verify.

\section{ACKNOWLEDGEMENTS}

A dining chair with the function of holding the neck forward flexion posture by the ideal posture holding method realized by acquiring new findings. The university headquarters that understands the great potential and the social contribution of the dining chair to support and protect the diet of the elderly people whose swallowing function continues to decline. I would like to thank the researchers who carried out the most objective evaluation results and the university headquarters that paid $90 \%$ of the verification fee.

\section{REFERENCES}

1. Michiwaki Y, Sumi Y. Estimated National Health Care Costs for Aspiration Pneumonia over 70 Years Old Inpatients. Gerontol.

2. Siebens AA. Rehabilitation for swallowing impairment. In: kottke FJ, Lehmann JF(eds) Handbook of Physical Medicine \& Rehabilitation, W.B.Sounders Company, USA,1990;765-777.

3. Kuramoto N, Jayatilake D, Hidaka K, Suzuki K. Smartphone-based swallowing monitoring and feedback device for mealtime assistance in nursing homes. Conf Proc IEEE Eng Med Biol Soc. 2016; 2016:5781-5784.

4. Naruse T, Ando T, Bando N. A study on the comfort evaluation and functional design of wooden chairs by the engineering method of the Horibe (vi) on the angle of back seat suitable for work chairs. Gifu Institute of Living Technology, 2004.

5. Inui R, Morikiyo K, Nakajima T. Muscle activity in swallowing muscles and cervical muscles during swallowing of neck angle change Influence on Japan. J Dysphagia Rehab.2012;16(3): 269-275.

6. Okitsu T, Arita M, Sonoda S, Ota T, Hotta F, Honda T, et al. The surface electromyography on suprahyoid muscles during swallowing. Jpn J Rehabil Med. 1998;35(4):241-244.

7. Sakuma T, Kida I. Relationship between ease of swallowing and deglutition-related muscle activity in various postures. J Oral Rehabil. 2010;37(8):583-589.

8. Woo HS, Park SH, Jung MY, Yoo EY, Park JH. The effects of cranio-cervical flexion on activation of swallowing-related muscles. J Oral Rehabil. 2012;39(11):805-811.

9. Schultheiss C, Wolter S, Schauer T, Nahrstaedt H, Seidl RO. Effect of body position on coordination of breathing and swallowing. HNO. 2015;63(6):439-446. 